\title{
A Compensator Designed for Electro-Hydraulic Servo System in Laminar State
}

\author{
Le ZENG***, Jianping TAN*, Jun YANG*** \\ * State Key Laboratory of High Performance Complicated Manufacturing, College of Mechanical and Electrical \\ Engineering, Central South University, Chinalco technology building, new campus of Central South University, \\ Yuelu District, Changsha 410083, China, E-mail: jptan@163.com \\ **Changsha Aeronautical Vocational and Technical College, Tianxinqiao, Yuhua District, Hunan Province, Changsha \\ 410124, China, E-mail: zenglewish@163.com \\ ***College of Engineering and Design, Hunan Normal University, College of engineering and design, Taozihu Road, \\ Yuelu District, Changsha 410081, China, E-mail: yangcsu@126.com (Corresponding Author) \\ crossref http://dx.doi.org/10.5755/j02.mech.26023
}

\section{Introduction}

The electro-hydraulic servo system (EHSS) is widely used in national defences, industrial equipment, construction machinery, mining machinery, metallurgy machinery, forging machinery, and robot system [1-3]. The EHSS is affected by friction, dead zone, oil compressibility, internal leakage and other factors, and has the problems of uncertain model parameters. In order to maximize the accuracy, response speed and robustness of the electro-hydraulic system, many nonlinear control methods such as adaptive control [4], robust control [5], predictive control [6, 7], feedback linearization control [8,9], sliding mode variable structure control [10-13], intelligent control [14, 15] are applied to the hydraulic control. Literature [16] pointed out that the non-linearity of valve controlled cylinder system is mainly caused by the non-linearity of valve orifice flow, which is the square root of the pressure difference. The effect of external load force directly affects the pressure difference of the servo valve orifice, thus affecting the output of flow and the displacement speed response of hydraulic cylinder.

In order to reduce the complex calculation of the control strategy and make it used in the industrial field, more scholars use the differential pressure compensation to suppress the speed fluctuation caused by the load disturbance. In literature $[17,18]$, the strategy of differential pressure and flow compensation was adopted earlier so that the flow of control system and the speed of motor were not affected by the load. Yang H.Y. [19] designed flow compensation control of the valve port strategy based on PLC. Quan L., Bai Y.H. [20, 21] adopted a composite control strategy of speed feedforward and position feedback to realize the desired control performance of speed and position under different loads. In the research the submerged orifice flow equation is used to describe the flow through the valve orifice under a certain pressure difference, and the flow coefficient is taken as a constant. But when the pressure difference or the opening of the valve orifice is very small, the flow state is laminar with low Reynolds number and the flow coefficient is a non-linear variable [22]. So the submerged orifice flow equation is difficult to describe the flow with low Reynolds number. The error of the system model leads to the poor performance of load flow compensation control, especially when the system is subjected to excessive load relative to the maximum load of the system or small target displacement. Literature [23] shows that with the increase of external load, the accuracy of the compensator designed by empirical flow equation model decreases. Because the pressure difference between of the valve port decreases with the external load increases, the flow coefficient changes, and the accuracy of flow compensation decreases.

Ferreira J. A. [24] divided the valve model into dynamic response area and static response area. The valve orifice in the small opening state has serious nonlinearity, which is the dynamic response area. This paper analysed the load flow gain and load pressure gain of the valve controlled symmetrical cylinder system in the small opening state and the large opening state, and designed the closed-loop control for the composite model. Andreas S. [25] pointed out that the flow coefficient of the valve is related to the manufacturing accuracy of the valve and the wear of the valve. In this paper, the flow characteristic of the servo valve is tested by experiment, and the flow coefficient of the valve is estimated to determine the wear and failure of the valve. From the flow characteristic curve obtained by the experiment, it can be seen that the flow characteristic of the servo valve in the small opening state is nonlinear. Borutzky W. [25] analyses the correlation of flow coefficient and Reynolds number of servo valve. When the pressure difference is small, the flow state of the servo valve port is laminar, and the flow model is quite different from the turbulent state. Pan X.D. [26] conducted flow field simulation and experimental analysis on the flow coefficient of rectangular slide valve, obtained the function relationship between flow coefficient and Reynolds number, and established a more accurate flow model of small opening state of servo valve.

In order to improve the accuracy of load flow compensation control in the electro-hydraulic servo system, this paper analyses the laminar flow and turbulent flow state of the servo valve, and studies the load flow equation in the laminar flow state with small opening or small pressure difference of the valve orifice. Based on the expected linear flow equation and the laminar flow equation, a flow compensator is designed to compensate the flow affected by pressure difference, which makes the flow characteristics linear. It can be used as an open-loop controller to resist the nonlinearity of valve and form a composite control strategy with closed-loop control strategies to improve the accuracy of the system. 


\section{The flow model of the servo valve}

The flow state of the servo valve can be regarded as viscous incompressible flow, and the flow under a certain pressure difference can be calculated by the submerged flow calculation formula as follows:

$$
Q=C_{d} A \sqrt{\frac{2 \Delta P}{\rho}}
$$

where: $Q$ is volume flow through valve orifice, $\mathrm{m}^{3} / \mathrm{s} ; \Delta p$ is pressure difference of valve orifice, $\mathrm{Pa} ; \rho$ is hydraulic oil density, $\mathrm{kg} / \mathrm{m}^{3} ; C_{d}$ is flow coefficient; $A$ is flow area of valve orifice, $\mathrm{m}^{2}$. The ideal rectangular notch throttle orifice area in spool valve can be calculated as $A=\omega x_{v}$, where $x_{v}$ is orifice opening size, $\mathrm{m}$; $\omega$ is orifice area gradient.

Numerical simulation results demonstrate that the relationship between flow coefficient $C_{d}$ and Reynolds number $R_{e}$ of the servo valve is approximated as Eq. (2), which was researched by Borutzky, W. and Pan, X. in [26, 27].

$$
C_{d}=C_{d t} \sqrt{\frac{R_{e}}{R_{e}+R_{c}}}
$$

where: $C_{d t}$ is flow coefficient in turbulent state; $R_{c}$ is critical Reynolds number.

The following equation can be derived from Eqs. (1) and (2).

$$
Q=C_{d t} \sqrt{\frac{R_{e}}{R_{e}+R_{c}}} w x_{v} \sqrt{\frac{2 \Delta p}{\rho}} .
$$

The Reynolds number $R_{e}$ is a dimensionless number, and can be defined by H. E. Merritt in [28].

$$
R_{e}=\frac{d_{H}}{A v} Q
$$

where: $v$ is kinematic viscosity of fluids; $d_{H}$ is hydraulic diameter.

The hydraulic diameter $d_{H}$ of the spool valve orifice can be defined as:

$$
d_{H}=\frac{4 A}{\lambda}=\frac{2 A}{\omega+x_{v}}
$$

where: $\lambda$ is wetted perimeter of the overflow surface.

The Reynolds number $R_{e}$ can be obtained from Eqs. (4) and (5).

$$
R_{e}=\frac{2 Q}{v\left(\omega+x_{v}\right)}
$$

When the pressure difference $\Delta p$ and the opening of the valve $x_{v}$ is very small, even close to zero, the flow $Q$ and the Reynolds number $R_{e}$ is too small and the flow state is laminar. As the pressure difference $\Delta p$ or the opening of the valve $x_{v}$ increases, the Reynolds number $R_{e}$ and the flow coefficient $C_{d}$ increases. When the Reynolds number $R_{e}$ is much larger than the critical Reynolds number $R_{c}, C_{d t} \approx C_{d}$. The flow coefficient keeps nearly stable, and the flow pattern has negligible effect on the flow rate of the valve.

Substituting the Eq. (6) into the Eq. (3) gives a quadratic equation for the flow.

$$
2 Q^{2}+R_{c}\left(w+x_{v}\right) v Q-\frac{4\left(C_{d t} w x_{v}\right)^{2} \Delta p}{\rho}=0 .
$$

Solving this quadratic equation and discarding the negative root, the orifice discharge $Q$ can be obtained as:

$$
\begin{aligned}
& Q=\frac{\sqrt{\left[R_{c}\left(\omega+x_{v}\right) v\right]^{2}+\frac{32\left(C_{d t} \omega x_{v}\right)^{2} \Delta p}{\rho}}}{4}- \\
& -\frac{R_{c}\left(\omega+x_{v}\right) v}{4} .
\end{aligned}
$$

The orifice discharge $Q$ is approximately to $Q=C_{d t} w x_{v} \sqrt{\frac{2 \Delta P}{\rho}}$ when the pressure difference $\Delta p$ or the opening of the valve $x_{v}$ is large enough to make the valve orifice turbulent.

\section{The expected flow equation}

The nonlinearity of flow increases the difficulty of the electro-hydraulic system control. If the flow gain of the servo valve is constant, the complexity of the electro-hydraulic system model and the controller can be greatly reduced under the premise of guaranteeing control performance. For this reason, the desired flow equation of the servo valve is presented as shown in Eq. (9):

$$
Q^{\prime}=C_{d t} \omega \sqrt{\frac{2}{\rho}}\left(\frac{P_{\mathrm{S}}-P_{R}}{2}\right)^{1 / 2} x_{V}
$$

where: $P_{S}$ is $P$ port pressure of the servo valve; $P_{R}$ is $T$ port pressure of the servo valve. If the $P$ port pressure and the $T$ port pressure are stable, the flow gain $C_{d t} \omega \sqrt{\frac{2}{\rho}}\left(\frac{P_{\mathrm{S}}-P_{R}}{2}\right)^{1 / 2}$ of the expected flow equation is constant, and the flow rate is independent of the pressure difference $\Delta P$ of the valve orifice and linear with the valve orifice opening.

\section{The design of a compensation controller}

To make the output flow of the servo valve close to the expected state, a compensation controller is designed to compensate the non-linear flow caused by laminar state. The orifice opening of the servo valve after compensation is set as $x_{v}{ }^{\prime}$, and the function of the orifice opening before and after compensation is set as following:

$$
x_{v}^{\prime}=f\left(x_{v}\right) \text {. }
$$

To make the actual output flow $Q$ equal to the ex- 
pected discharge $Q^{\prime}$, the simultaneous (8), (9) and (10) formula. After substituting Eq. (10) into the Eq. (8) and making

$$
\begin{aligned}
& \frac{\sqrt{\left[R_{c}\left(\omega+f\left(x_{v}\right)\right) v\right]^{2}+\frac{32\left(C_{d t} \omega f\right.}{\rho}}}{4} \\
& \frac{\beta \gamma}{\alpha}\left(1+\sqrt{1+32 \frac{\alpha^{2}}{\gamma^{2}}+16 \frac{\alpha}{\gamma \beta} \frac{w}{x_{v}}}\right) \frac{x_{v}}{x_{v \max }},
\end{aligned}
$$

where: $\alpha=C_{d t} w \sqrt{\frac{\Delta p}{\rho}}, \beta=\sqrt{\frac{P_{S}-P_{R}}{\Delta p}}$ and $\gamma=R_{c} v$.

Assuming that the current or voltage given to the servo valve is linearly related to the valve orifice opening, the percentage of the current (voltage) to the maximum current (voltage) is set as $u$ before compensation, and $u^{\prime}$ after compensation. Percentage of input signal before compensation $u$ can be described as:

$$
u=\frac{x_{v}}{x_{v \max }} .
$$

Percentage of the input signal $u^{\prime}$ after compensation can be described as:

$$
u^{\prime}=\frac{x_{v}^{\prime}}{x_{v \max }}
$$

Eq. (8) and Eq. (9) equal, the following equation can be obtained:

$$
-\frac{R_{c}\left(\omega+f\left(x_{v}\right)\right) v}{4}=C_{d t} \omega \sqrt{\frac{2}{\rho}} \sqrt{\frac{P_{\mathrm{S}}-P_{R}}{2}} x_{V} .
$$

Substituting Eqs. (13) and (14) into the Eq. (12), percentage of input signal $u$ ' after compensation can be obtained as:

$$
u^{\prime}=\frac{\beta \gamma}{8 \alpha}\left(1+\sqrt{1+32 \frac{\alpha^{2}}{\gamma^{2}}+16 \frac{\alpha}{\gamma \beta} \frac{w}{x_{v \max }} \frac{1}{u}}\right) u .
$$

The compensating controller is designed according to Eq. (15) to compensate the non-linear flow affected by flow pattern, so that the actual flow output of the servo valve is equal to the expected flow. Namely, the flow output of the servo valve is linear with the opening of the valve orifice.

\section{Load flow model of EHSS}

The diagram of EHSS is shown in Fig. 1. The load flow is the flow into or out of the rodless cavity. Specifically, it is the flow into the rodless cavity when the cylinder is in forward motion, and the flow out of the rodless cavity but when the cylinder is in reverse motion.

According to Eq. (7), the equation of the load flow of the system $Q_{L}$ is described:

$$
Q_{L}=\frac{\sqrt{\left[R_{c}\left(\omega+x_{v}\right) v\right]^{2}+\frac{32\left(C_{d t} \omega x_{v}\right)^{2} \Delta p}{\rho}}}{4}-\frac{R_{c}\left(\omega+x_{v}\right) v}{4} .
$$

where: $\Delta p=P_{S}-P_{1}$, when $0 \leq x_{v} \leq L$. While, $\Delta p=P_{1}-P_{R}$, when $-L \leq x_{v}<0$. $L$-the maximum opening of the valve orifice.

Literature [29] studies that the flow coefficient of a throttle valve is related to the direction of fluid flow. In order to reduce the complexity of control, the influence of flow coefficient of inflow and outflow is neglected. Through the compensation control of Eq. (14), the load flow can be theoretically controlled in accordance with the expected flow equation, that is, the load flow does not change with the external load and direction of the hydraulic rod.

\section{Experiment}

\subsection{The experimental bench}

The experimental bench shown in Fig. 2 is built according to the scheme shown in Fig. 1.

The bench consists of driving circuit of the servo valve-controlled asymmetric cylinder system and load circuit of the relief valve-controlled asymmetric cylinder. The external load is simulated by adjusting the overflow pressure of the relief valve, and the pressure difference of the valve orifice can be controlled. The flow output of the valve orifice is calculated by detecting the velocity of the hydraulic cylinder.

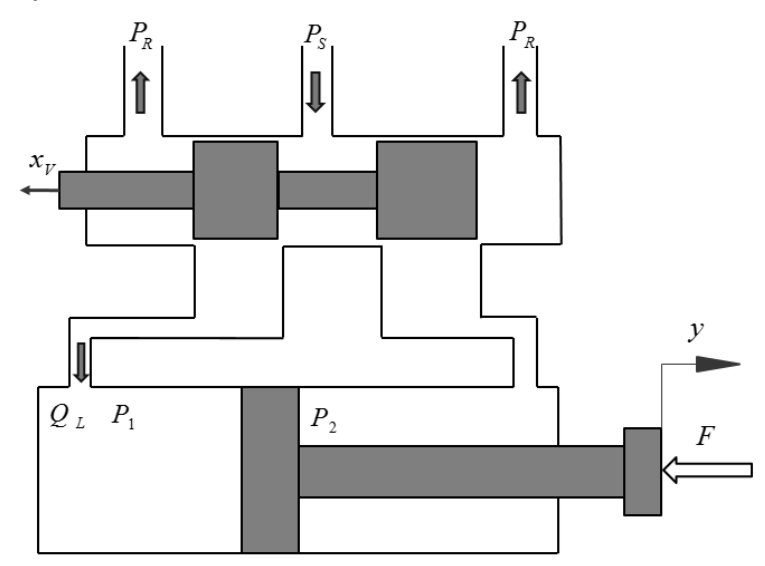

Fig. 1 The diagram of EHSS: $P_{1}$ is pressure of the rodless cavity; $P_{2}$ is pressure of the rod cavity; $Q_{L}$ is the load flow; $y$ is displacement of the rod; $F$ is external load

The basic system parameters of the bench are shown in Table 1. According to literature [26], the value $C_{d t}$ 
is 0.61 ; according to the literature [31] and test, the value $R_{c}$ is 170; the pressure value $P_{s}$ is approximately equal to the pump outlet pressure set as $5 \mathrm{MPa} . P_{R}$ is approximately equal to the tank pressure set as $0 \mathrm{MPa}$. $P_{1}, P_{2}$ is detected by the pressure sensor.

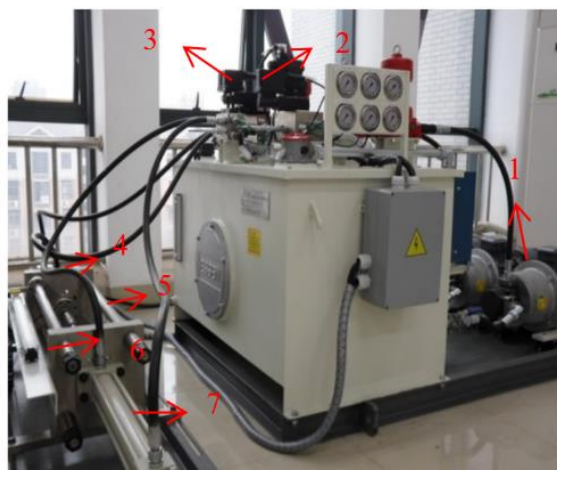

Fig. 2 The experimental bench: 1 is hydraulic pumping station; 2 is the servo valve; 3 is proportional relief valve; 4 is load cylinder; 5 is connection between top cylinder; 6 is position sensor; 7 is driving cylinder

Table 1

The basic system parameters

\begin{tabular}{|l|l|}
\hline Parameter, Measurement unit & Value \\
\hline System pressure, MPa & 5 \\
\hline Pump speed, $\mathrm{r} / \mathrm{min}$ & 960 \\
\hline Pump displacement, $\mathrm{ml} / \mathrm{r}$ & 16 \\
\hline$\rho, \mathrm{kg} / \mathrm{m}^{3}$ & 850 \\
\hline $\begin{array}{l}\text { Nominal flow of servo valve under differential } \\
\text { pressure 3MPa, L/min }\end{array}$ & 9 \\
\hline Frequency of the servo valve, $\mathrm{Hz}$ & 100 \\
\hline Radius of Hydraulic cylinder, $\mathrm{m}$ & 0.05 \\
\hline Rod diameter hydraulic cylinder, $\mathrm{m}$ & 0.028 \\
\hline$v, \mathrm{~m}^{2} / \mathrm{s}$ & $6 \times 10^{-5}$ \\
\hline$L, \mathrm{~m}$ & $0.5 \times 10^{-3}$ \\
\hline$w, \mathrm{~m}$ & $9.23 \times 10^{-3}$ \\
\hline
\end{tabular}

\subsection{Characteristics experiment of the servo valve}

\subsubsection{The flow characteristics of the servo valve in lami- nar state}

When the pressure difference or the opening of the servo valve is small, the flow of the valve is laminar and in the low Reynolds state. So the test area is mainly carried out in the small opening of servo valve. In the experiment, the input signal of the valve is - $15 \%$ to $15 \%$ of the maximum rated voltage, and the signal interval is $1 \%$. The pressure difference of the valve orifice is achieved by imposing external load to the driving cylinder. Fig. 3 shows the flow of the valve under the pressure difference of $0.5 \mathrm{MPa}, 1.0 \mathrm{MPa}$, 1.5 $\mathrm{MPa}, 2.0 \mathrm{MPa}, 2.5 \mathrm{MPa}, 3.0 \mathrm{MPa}$.

The flow coefficient $C_{d}$ can be obtained by transforming Eq. (1):

$$
C_{d}=\frac{Q}{A} \sqrt{\frac{\rho}{2 \Delta P}} .
$$

According to Eq. (17) and the flow data in Fig. 3, the flow coefficient $C_{d}$ of the valve is calculated as shown in Fig. 4. When the pressure difference is $0.5 \mathrm{MPa}$, and 1.0 $\mathrm{MPa}$, the value of the $C_{d}$ is far less than the value with larger pressure difference. As the pressure difference increases, the difference of $C_{d}$ decreases. In addition, when the valve opening is small, the $C_{d}$ value is small. As the valve opening increases, the $C_{d}$ value increases, approaching to constant value in the turbulent state model.

In the experiment of flow characteristics with small opening, the change of flow coefficient shows that the flow state of the valve is laminar flow when the opening and the pressure difference is small, and the flow coefficient $C_{d}$ is far less than the constant value of 0.61 .

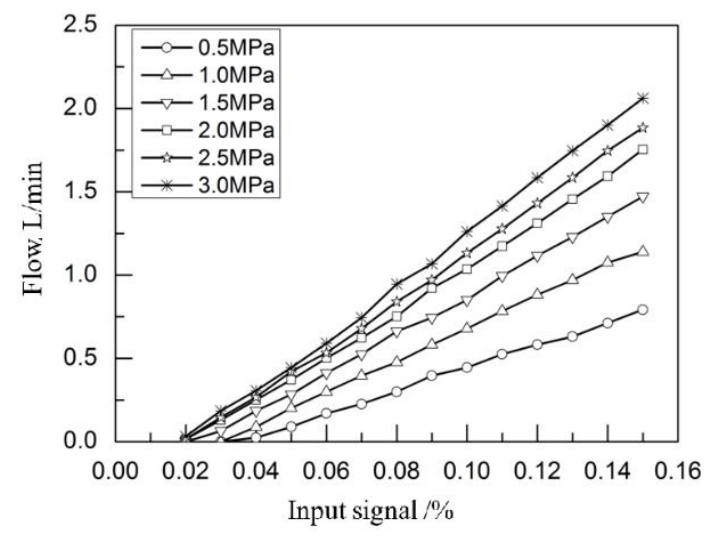

Fig. 3 The flow characteristic of the valve in laminar state

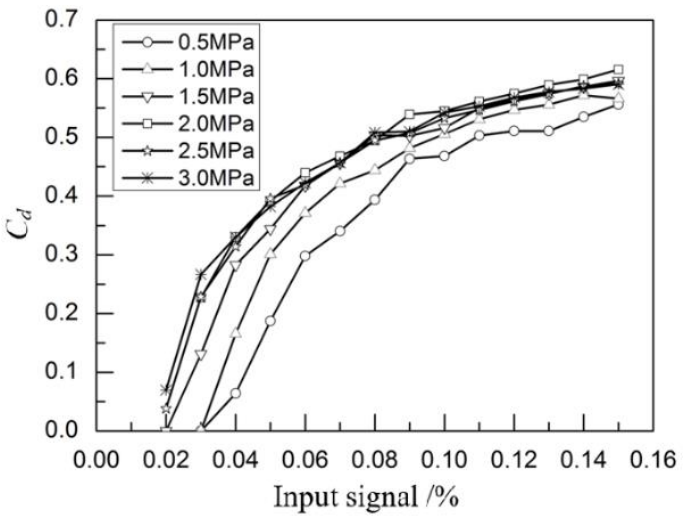

Fig. 4 The flow characteristic of the valve in laminar state

\subsubsection{The flow characteristics experiment after compensa- tion control}

The pressure difference of the valve orifice varies from $0.5 \mathrm{MPa}$ to $4 \mathrm{MPa}$, through imposing external load to the driving cylinder. The control system collects data of the signal input value, pressure value of two chambers and velocity of hydraulic cylinder before and after compensation control. Characteristics experiment is to verify that the compensation controller can make the flow characteristics of the servo valve close to the expected flow characteristics.

Fig. 5 shows the expected load flow curve and the load flow curve after compensation control. Through comparison, it can be seen that the load flow after compensated is linear with the valve orifice opening, and basically close to the expected load flow.

The error diagram is shown in Fig. 6. Because of the negative overlap of the servo valve at about $2 \%$, the error is large when the orifice opening is about $1 \%$ 3\%. With the increase of the orifice opening, the error decreases rapidly and is controlled within $20 \%$. Because the flow coefficient of the valve orifice is related to the direction of the liquid 
flow, the error distribution is asymmetric compared to the valve orifice opening $2 \%$.

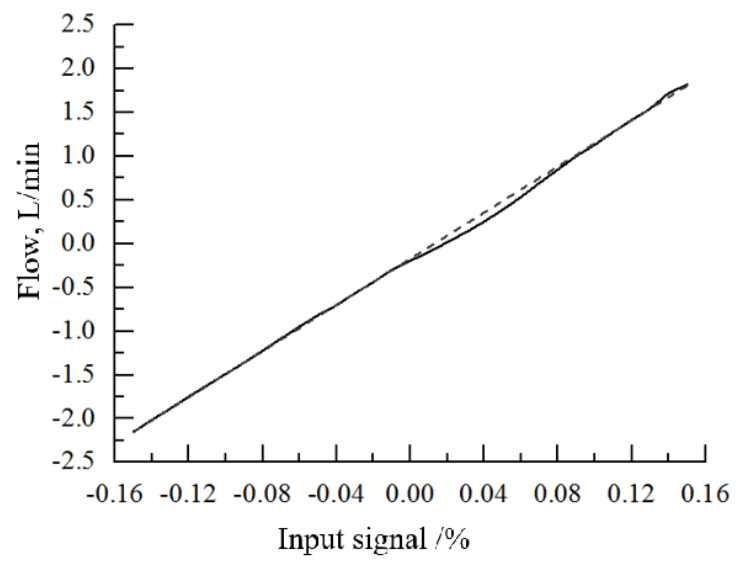

Fig. 5 The expected flow and load flow characteristic after compensation control: dash line represents the expected flow line through theoretical calculation; solid line represents the actual flow after compensated of the test bench

When the input signal is $5 \%$, the load flow before and after compensation control is compared with the curve of pressure difference. Fig. 7 shows that the pressure difference of the valve orifice changes from $0.5 \mathrm{MPa}$ to $4 \mathrm{MPa}$, and the load flow after compensation almost keeps stable which is shown in Fig. 9, while the uncompensated load flow decreases with the decrease of the pressure difference. When the pressure difference is less than $2 \mathrm{MPa}$, the load flow changes obviously with the pressure difference. In order to compensate the flow change caused by load, the compensation signal increases obviously. When the pressure difference is only $0.5 \mathrm{MPa}$, the signal input value shown in Fig. 8 after compensation control reaches about $10 \%$. When the pressure difference is greater than $2.5 \mathrm{MPa}$, the load flow increases insignificantly, and the signal input after compensation control changes insignificantly, which decreases slightly relative to the signal of $5 \%$.

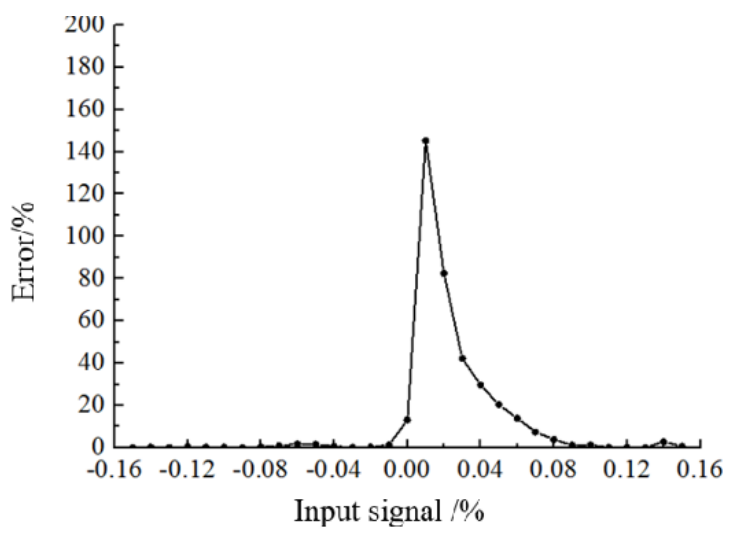

Fig. 6 Percentage error of expected load flow and load flow after compensation control

The characteristic experiment shows that when the pressure difference is small, the flow of the servo valve decreases obviously with the decrease of the pressure difference. When the pressure difference is large, the flow of the valve changes little with the pressure difference. The designed compensation controller can compensate the flow fluctuation well caused by external load, and make the flow characteristics of the servo valve approximate to the expected flow equation.

\subsection{Position control experiment}

\subsubsection{Experimental methods and purpose}

Given the sinusoidal displacement reference signal, whose amplitude is $5 \mathrm{~mm}$ and frequency is $0.5 \mathrm{~Hz}$, the $\mathrm{P}$ closed-loop controller is used to test the displacement response of the EHSS with large external load. By comparing the response of the system with and without open-loop compensator, the conclusion will verify that the open-loop compensator can improve the accuracy and the anti-load interference ability with the simplest closed loop control.

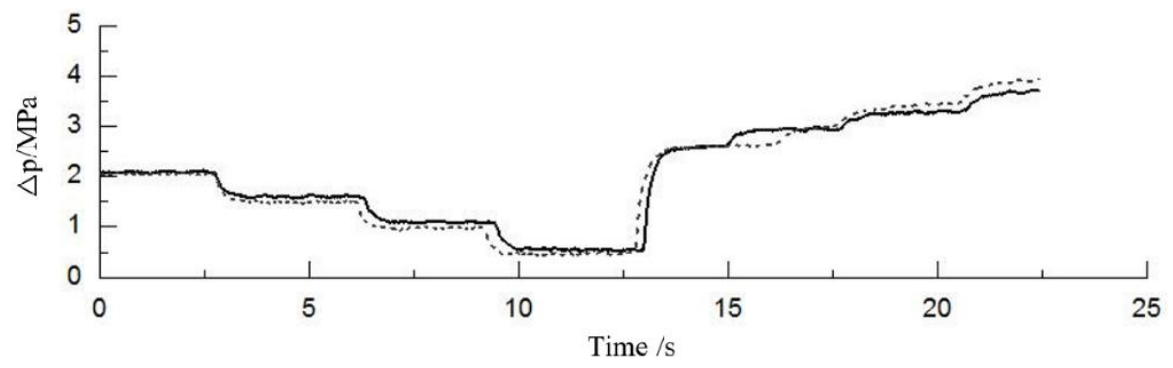

Fig. 7 The pressure difference of the valve orifice: solid line represents the pressure difference before compensation control; dash line represents the pressure difference after compensation control

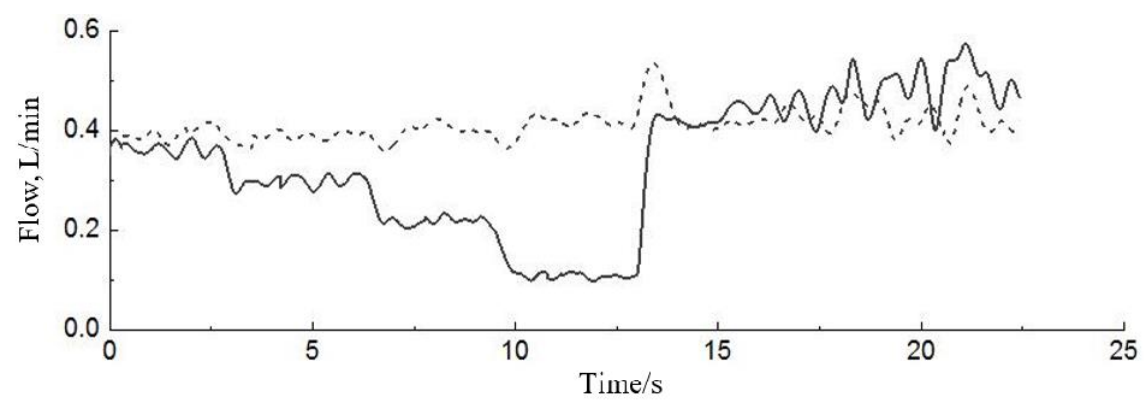

Fig. 8 The signal input to the servo valve: solid line represents the flow before compensation control; dash line represents the flow after compensation control 


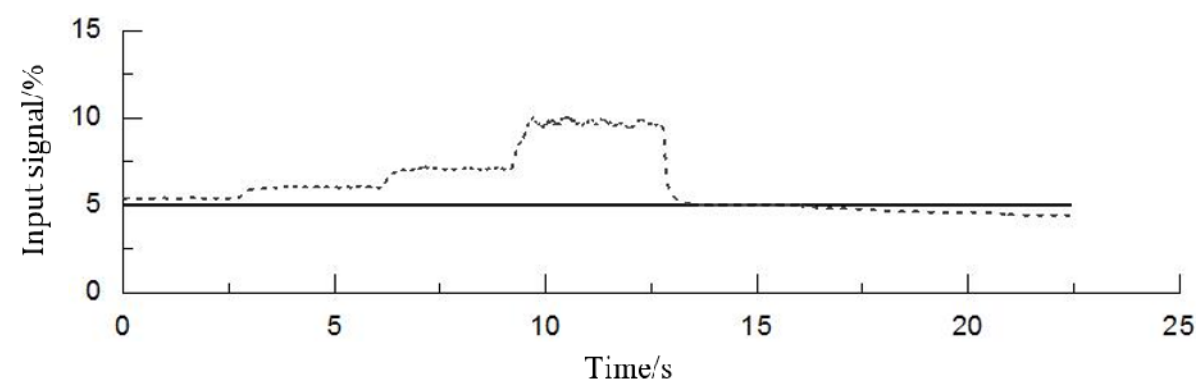

Fig. 9 The load flow through the valve orifice: solid line represents the input signal before compensation control; dash line represents the input signal after compensation control

\subsubsection{Experimental results}

Figs. 8-10 shows the response diagram of the system without compensation control. Fig. 8 shows the pressure variation diagram of two chambers in driving cylinder under excessive external load. The external load causes the pressure fluctuation of the rodless chamber in the driving cylinder from $2 \mathrm{MPa}$ to $4.2 \mathrm{MPa}$, that is, the pressure difference of the valve orifice is $0.8 \mathrm{MPa}$ to $3 \mathrm{MPa}$. Fig. 9 shows the response diagram of the cylinder tracking sinusoidal displacement signal.

Fig. 10 shows the displacement error diagram of the cylinder. From Fig. 10, it can be seen that the pressure change of the two chambers has a great influence on the motion control accuracy. When the pressure fluctuates at $2.5 \mathrm{MPa}$, that is, the pressure difference of the valve orifice is about $2.5 \mathrm{MPa}$, the maximum error is less than $5 \mathrm{~mm}$. When the pressure reaches $4 \mathrm{MPa}$, that is, the pressure difference is $1 \mathrm{MPa}$, the maximum error is $0.8 \mathrm{~mm}$.

Figs. 11-13 shows the system response diagram with compensator as feed control. Fig. 11 shows that the pressure of the rodless chamber in the driving cylinder fluctuates between $2 \mathrm{MPa}$ and 4.2 MPa under the influence of external load, that is, the pressure difference of the valve orifice fluctuates between $0.8 \mathrm{MPa}$ and $3 \mathrm{MPa}$. Figs. 12 and 13 show the response diagram and error of tracking sinusoidal displacement signal of the system using compensation control. Fig. 13 shows that the displacement error of hydraulic cylinder is controlled within $0.4 \mathrm{~mm}$ when the pressure difference is between $0.8 \mathrm{MPa}$ and $3 \mathrm{MPa}$. That is to say, compared with non-compensation control, the external load has little effect on the accuracy of the system with compensation control.

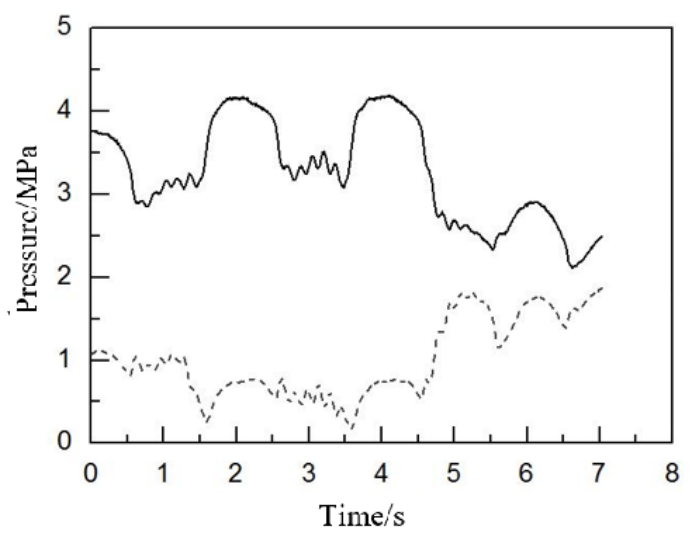

Fig. 8 The pressure variation diagram without compensation control: solid line represents the pressure in the rodless cavity; dash line represents the pressure in the rod cavity

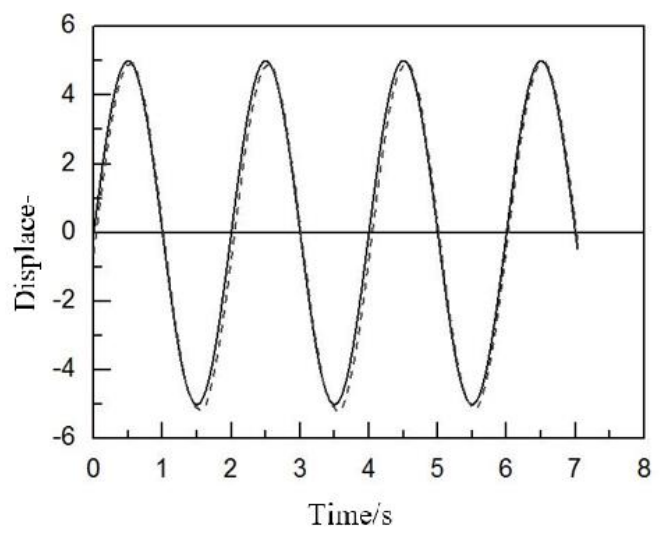

Fig. 9 Displacement response of the dive cylinder without the compensator: solid line represents the reference displacement; dash line represents the actual displacement

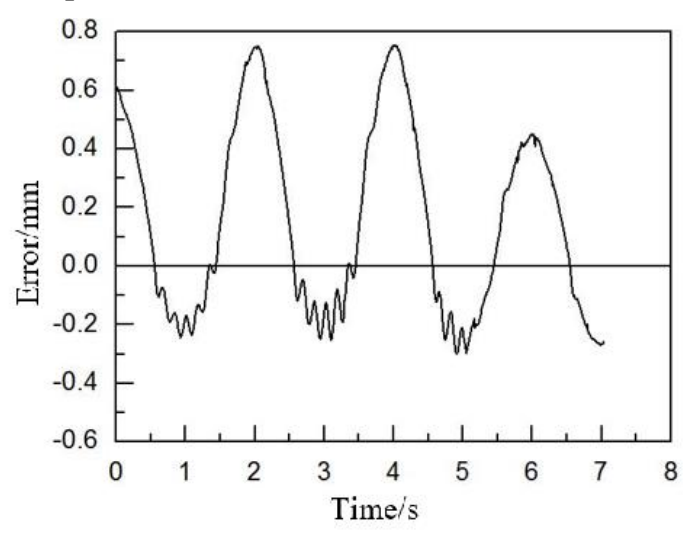

Fig. 10 The position error of the dive cylinder without the compensator

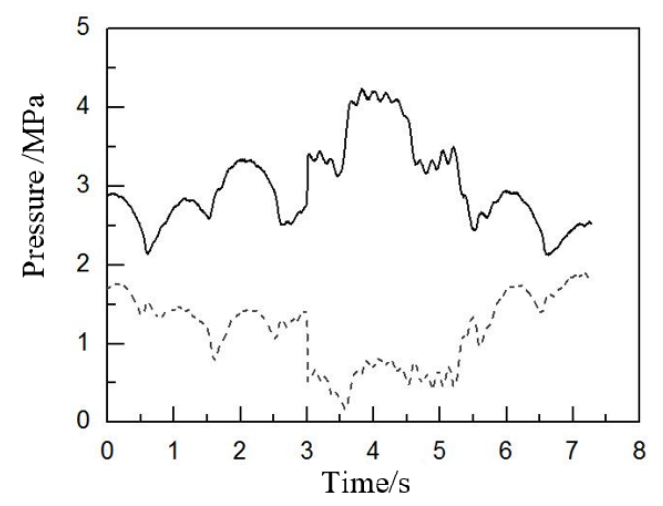

Fig. 11The pressure diagram in experiment with compensator: solid line represents the pressure in the rodless cavity; dash line represents the pressure in the rod cavity 


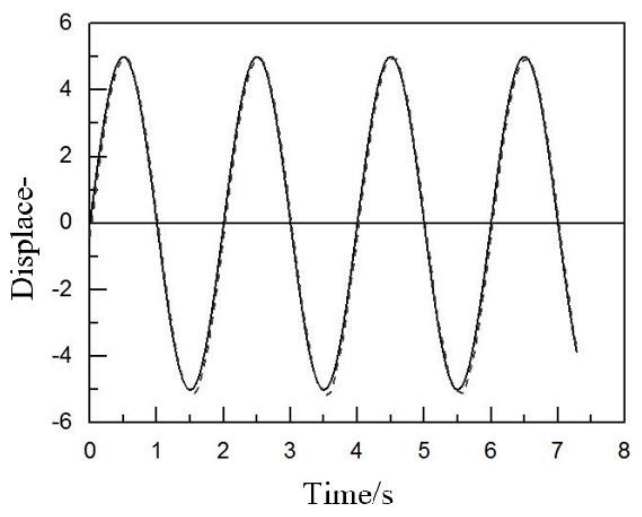

Fig. 12 The displacement of the dive cylinder with compensator: solid line represents the reference displacement; dash line represents the actual displacement

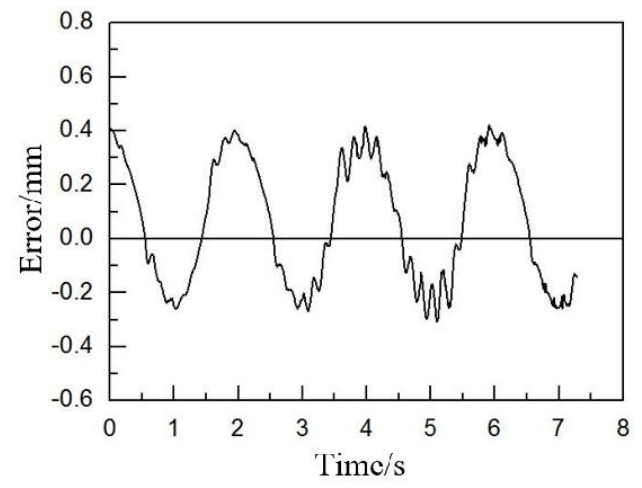

Fig. 13 The position error of the dive cylinder with compensator

Under the same control parameters, P closed loop control has realized the good motion response of EHSS tracking sinusoidal signal, whose amplitude is $5 \mathrm{~mm}$ and frequency is $0.5 \mathrm{~Hz}$. Experiment verified that the compensator can improve the position accuracy and the anti-load interference ability of the system, with the simplest closedloop control.

\section{Conclusions}

The Reynolds number is discussed which has a great influence on the flow of the valve orifice when the pressure difference and the opening of the valve is small. A novel flow equation of the valve orifice is built because the submerged flow equation cannot describe the flow accurately in the low Reynolds state. The novel flow equation is nonlinear with the orifice opening and pressure difference. The experimental results show that when the valve orifice is small or the pressure difference is small, the flow coefficient changes nonlinearly, which is far less than the constant value of 0.61 . The flow state of the valve orifice is laminar with low Reynolds number.

To eliminate the nonlinear factors of the flow characteristics of the servo valve, a compensator is designed by solving the equation of the novel flow and desired flow. The characteristics experiment verified the flow curve after compensation is close to the expected flow curve.

The open-loop compensator as feed forward control compounded with the simplest proportional (P) controller are used in EHSS under heavy load relatively to system pressure. The displacement reference signal is a sinusoidal signal, whose frequency is $0.5 \mathrm{~Hz}$ and amplitude is $5 \mathrm{~mm}$.
The experiment result shows that the compensator can greatly improve the position accuracy of the system, which the maximum error is less than $0.4 \mathrm{~mm}$. While, the maximum error of the system without compensator is $0.8 \mathrm{~mm}$.

By establishing feed forward compensation control of laminar flow state, the load flow nonlinearity of servo valve in extreme load state is eliminated, and the stability of the system for variable load is improved. The feed forward compensation with the simplest proportional closed-loop control can achieves a good control effect, which is suitable for industrial field control.

\section{References}

1. Guo, K.; Wei, J.; Fang, J.; et al. 2015. Position tracking control of electro-hydraulic single-rod actuator based on an extended disturbance observer, Mechatronics 27: 4756.

http://dx.doi.org/10.1016/j.mechatronics.2015.02.003.

2. Xiao, L.; Lu, B. 2015. Cascaded sliding mode force control for a single-rod electrohydraulic actuator, Neurocomputing 156: 117-120.

http://dx.doi.org/10.1016/j.neucom.2014.12.078.

3. Nguyen, M. N.; Tran, D. T.; Ahn, K. K. 2018. Robust position and vibration control of an electrohydraulic series elastic manipulator against disturbance generated by a variable stiffness actuator, Mechatronics 52: 22-35. https://doi.org/10.1016/j.mechatronics.2018.04.004.

4. Wang, C.; Quan, L.; Jiao, Z. 2017. Nonlinear adaptive control of hydraulic system with observing and compensating mismatching uncertainties, IEEE Transactions on Control Systems Technology 1-12. http://dx.doi.org/10.1109/TCST.2017.2699166.

5. Guo, Q.; Yu, T.; Jiang, D. 2015. Robust $H \infty$ positional control of 2-DOF robotic arm driven by electrohydraulic servo system, ISA Transactions 59: 55-64. http://dx.doi.org/10.1016/j.isatra.2015.09.014.

6. Jia, Z.; Ma, J.; Wang, F. 2011. Hybrid of simulated annealing and SVM for hydraulic valve characteristics prediction, Expert Systems with Applications 38: 80308036.

http://dx.doi.org/10.1016/j.eswa.2010.12.132.

7. Camacho, E. F.; Ramírez, D. R.; Limón, D. 2010. Model predictive control techniques for hybrid systems, Annual reviews in control 34: 21-31. https://doi.org/10.1016/j.arcontrol.2010.02.002.

8. Ayalew, B.; Jablokow, K. W. 2007. Partial feedback linearising force-tracking control: implementation and testing in electrohydraulic actuation, Control Theory \& Applications 1: 689-698.

https://doi.org/10.1049/iet-cta:20060186.

9. Seo, J.; Venugopal, R.; Kenné, J. P. 2007. Feedback linearization based control of a rotational hydraulic drive, Control Engineering Practice 15: 1495-1507. https://doi.org/ 10.1016/j.conengprac.2007.02.009.

10. Zinober, A. S. I.; Liu, G., Shtessel, Y. B. 2007.Slidingmode control in systems with output time delay. Mathematical Methods for Robust and Nonlinear Control, Lecture notes in control \& information sciences 367: 243-264. https://doi.org/ 10.1007/978-1-84800-025-4_9.

11. Feki, M. 2009. Sliding mode control and synchronization of chaotic systems with parametric uncertainties. Chaos, Solitons \& Fractals 41: 1390-1400. 
https://doi.org/ 10.1016/j.chaos.2008.05.022.

12. Kalsi, K.; Lian, J.; Hui, S. 2010. Sliding-mode observers for systems with unknown inputs: A high-gain approach, Automatica 46: 347-353.

https://doi.org/10.1016/j.automatica.2009.10.040.

13. Xiao, L. F.; Lu, B. B.; Yu, B.; Ye, Z. F. 2015. Cascaded sliding mode force control for a single-rod electrohydraulic actuator, Neurocomputin 156: 117-120. https://doi.org/ 10.1016/j.neucom.2014.12.078.

14. Kyoung, K. A.; Nguyen, H. T. 2007.Design of a robust force controller for the new mini motion package using quantitative feedback theory, Mechatronics 17:542-550. https://doi.org/ 10.1016/j.mechatronics.2007.07.011.

15. Shao, P. Z.; Fang, Y. M.; Wang, W. B.; Jiao, Z. X. 2012. Adaptive backstepping control of multi-model switching for the hydraulic servo position system of a rolling mill, Beijing Keji Daxue Xuebao/Journal of University of Science and Technology Beijing 34: 13461351.

16. Yang, J. H.; Li, S. Y.; Dai, Y. F. 2006. Research on robust control strategy of valve controlled asymmetric cylinder position servo system, Machine Tool \& Hydraulics 18: 2801-2805.

17. Jeyasenthil, R.; Choi, S. B.; Purohit, H. 2019. Robust position control and disturbance rejection of an industrial plant emulator system using the feedforwardfeedback control, Mechatronic 57: 29-38. https://doi.org/ 10.1016/j.mechatronics.2018.11.004.

18. Zhang, F. 2005. Adaptive compensation of hydraulic servo control system, Chinese Journal of Mechanical Engineering 05: 94-97.

http://dx.doi.org/10.3901/JME.2005.05.094.

19. Bo, Y.; Quan, L. 2010. Control strategy of the electrohydraulic position and speed hybrid servo system, Journal of Mechanical Engineering 24: 150-155. http://dx.doi.org/10.3901/JME.2010.24.150. http://dx.doi.org/10.1016/j.mechatronics.2018.11.004.

20. Eryilmaz, B.; Wilson, B. H. 2006. Unified modeling and analysis of a proportional valve, Journal of the Franklin Institute 343(1): 48-68.

http://dx.doi.org/10.1016/j.jfranklin.2005.07.001.

21. Fallahi, M.; Zareinejad, M.; Baghestan, K.; et al. 2018. Precise position control of an electro-hydraulic servo system via robust linear approximation, ISA Transactions 80: 503-512. https://doi.org/10.1016/j.isatra.2018.06.002.

22. Ramamurthi, K.; Nandakumar, K. 1999. Characteristics of flow through small sharp-edged cylindrical orifices, Flow Measurement and Instrumentation 10(3): 133-143. http://dx.doi.org/10.1016/s0955-5986(99)00005-9.

23. Zeng, L.; Yang, J.; Tan, J. P. 2017. Compensation control of a non-zero open valve controlled asymmetric cylinder system based on model invariance, Journal of Huazhong University of Science and Technology (Natural Science Edition) 45: 29-34. http://dx.doi.org/10.13245/j.hust.170305.

24. Ferreira J. A.; Almeida Fernando Gomes De; Quintas Manuel Rodrigues. 2002. A Semi-Empirical Model for a Hydraulic Servo-Solenoid Valve 216: 237 -
248.

https://doi.org/ 10.1243/095965102320005409.

25. Steinboeck, A.; Kemmetmüller, W.; Lassl, C.; Kugi, A. 2013. Model-based condition monitoring of an electro-hydraulic valve. journal of dynamic systems, Measurement and Control 135: 061010-061010.

https://doi.org/ 10.1115/1.4024800.

26. Borutzky, W.; Barnard, B.; Thoma, J. 2002. An orifice flow model for laminar and turbulent conditions. Simulation Modelling, Practice and Theory 10(3-4): 141-152. http://dx.doi.org/10.1016/S1569-190X(02)00092-8.

27. Pan, X.; Wang, G.; Lu, Z. 2011. Flow field simulation and a flow model of servo-valve spool valve orifice, Energy Conversion and Management 52(10): 3249-3256. http://dx.doi.org/10.1016/j.enconman.2011.05.010.

28. Merritt, H. E. 1976. Hydraulic Control Systems. Wiley $\&$ Sons.

29. Ji, H.; Zhang, J.; Wang, D. 2010. Flow coefficient of rectangular notch throttle orifice in spool valve, Journal of Lanzhou University of Technology 36(03): 47-50. http://dx.doi.org/ 10.1360/972009-1551.

30. Kumar, B.; Mittal, S. 2006. Prediction of the critical Reynolds number for flow past a circular cylinder, Computer Methods in Applied Mechanics \& Engineering 195: 44-47.

http://dx.doi.org/ 10.1016/j.cma.2005.10.009.

\section{Zeng, J. Yang, J. Tan}

\section{A COMPENSATOR DESIGNED FOR ELECTRO- HYDRAULIC SERVO SYSTEM IN LAMINAR STATE}

S u m m a r y

The study researched the orifice flow equation when the flow state of the orifice is laminar. Based on the novel flow equation and the expected linear flow equation, a compensator is designed to compensate the non-linearity and make the flow characteristics linear. The characteristics experiment result shows that the flow after compensation control is close to the expected flow, in which the pressure difference was increased from $0.5 \mathrm{MPa}$ to $4 \mathrm{MPa}$, and the error is less than $20 \%$. When the compensator is used as feed forward control in the EHSS and compound with proportional $(\mathrm{P})$ control, the sinusoidal response error with frequency of $0.5 \mathrm{~Hz}$ and amplitude of $5 \mathrm{~mm}$ is within $0.4 \mathrm{~mm}$ under large external load. While the error of the uncompensated system is up to $0.8 \mathrm{~mm}$. The compensator can be used into the electro-hydraulic system with larger load disturbance and improve the control performance compounded with the simplest proportional $(\mathrm{P})$ controller.

Keywords: laminar state, pressure difference, electro-hydraulic servo system, flow characteristics, feed forward control, compound control.

Received May 11, 2020 Accepted April 07, 2021 